\title{
LETTER TO THE EDITOR \\ Re: Incidence of pulmonary embolism after the first 3 months of spinal cord injury
}

Spinal Cord (2016) 54, 908; doi:10.1038/sc.2016.16; published online 5 April 2016

Alabed et al. ${ }^{1}$ reported the incidence of pulmonary embolism (PE) in spinal cord injury (SCI) patients over a 6-year period after anticoagulant therapy was stopped. The authors state that 'The incidence of pulmonary embolism (PE) after the initial months post injury is poorly reported in the literature'. They say that the incidence of PE after 90 days post SCI is lower than in the literature, quoting Geerts et al. ${ }^{2}$ and Aito et al. ${ }^{3}$

One of us, John Silver, initiated anticoagulant therapy for the prevention of PE in SCI patients in 1968. We have been interested in this problem of the duration that anticoagulation should be given, for the last 45 years. We wish to draw the authors' attention to the work carried out in an acute ward of Stoke Mandeville Hospital.

One hundred consecutive male spinal injury patients were studied between 15 April 1971 and 17 March 1973. ${ }^{4}$ One patient who had stopped anticoagulant therapy had a PE.

The problem was revisited in 1981, when in the same ward 102 consecutive male SCI patients were admitted between May 1976 and July 1979, and the results analysed. ${ }^{5}$ Sixty-six patients were anticoagulated, and 36 were not due to various contraindications. Anticoagulant therapy was discontinued after 3 months, and two patients who had received the recommended regime of anticoagulation therapy had emboli following the cessation of therapy.

Perkash et al. ${ }^{6}$ reported on 50 consecutive cases of acute SCI at the Veterans Administration Hospital in Palo Alto, CA. Two of these patients had pulmonary emboli after cessation of anticoagulant therapy.

The patients who did not have a PE were admitted and anticoagulated early after injury. The duration of anticoagulant therapy was controversial, and we recommended that anticoagulant treatment should be continued for 6 months and not 3 months in high-risk cases.

\section{CONFLICT OF INTEREST}

The authors declare no conflicts of interest.

JR Silver ${ }^{1}$ and WS El Masri ${ }^{2}$

${ }^{1}$ Stoke Mandeville Hospital, Aylesbury, Buckinghamshire, UK and ${ }^{2}$ Robert Jones and Agnes Hunt Orthopaedic Hospital, Keele University, Oswestry, Shropshire, UK E-mail: jrussellsilver@btconnect.com

1 Alabed S, de Heredia LL, Naidoo A, Belci M, Hughes RJ, Meagher TM. Incidence of pulmonary embolism after the first 3 months of spinal cord injury. Spinal Cord 2015; 53: 835-837.

2 Geerts WH, Bergqvist D, Pineo GF, Heit JA, Samama CM, Lassen MR et al. Prevention of venous thromboembolism: American College of Chest Physicians evidence-based clinical practice guidelines (8th Edition). Chest 2008; 133: 381S-453S.

3 Aito S, Pieri A, D'Andrea M, Marcelli F, Cominelli E. Primary prevention of deep venous thrombosis and pulmonary embolism in acute spinal cord injured patients. Spinal Cord 2002; 40: 300-303.

4 Silver JR. The prophylactic use of anticoagulant therapy in the prevention of pulmonary emboli in one hundred consecutive spinal injury patients. Paraplegia 1974; 12: 188-196.

5 EL Masri WS, Silver JR. Prophylactic anticoagulant therapy in patients with spinal cord injury. Paraplegia 1981; 19: 334-342.

6 Perkash A, Prakash V, Perkash I. Experience with the management of thromboembolism in patients with spinal cord injury: part I. Incidence, diagnosis and role of some risk factors. Paraplegia 1978; 16: 322-331. 